\title{
Nonlinear relationship between carbon market and energy market
}

\author{
Yan $\mathrm{Li}^{1 *}$ \\ ${ }^{1}$ Henan University, Business School, China
}

\begin{abstract}
This paper divides the energy market into energy futures market and new energy stock market. At the same time, the closing price of Shenzhen carbon emission rights is used to represent the carbon market price, the energy futures composite index of China Securities Exchange is used to represent the energy futures market price, and the stock price of new energy listed companies is used to represent the new energy stock market price. VAR model and MSVAR model are used to empirically study the relationship between the three variables and the nonlinear relationship between them. VAR model results show that there will be more complex relationship among carbon market price, energy company stock price and energy futures price. MSVAR model shows that the energy futures market, new energy stock market and carbon market present nonlinear and structural changes, and MSVAR model can better explain the nonlinear relationship among the three markets than traditional VAR model.
\end{abstract}

\section{1 introduction}

In recent years, with the global warming and frequent extreme weather, energy conservation and emission reduction have become the consensus of people all over the world. At present, China is preparing to further improve the carbon emission market system and launch the national carbon emission trading market, which will make the carbon emission trading exert more and more influence on the whole social economy and subjects at all levels. Energy market is composed of energy stock market and energy futures market, so it is of great theoretical and practical significance to explore the relationship between carbon emission trading, energy stock market and energy futures market.

Foreign scholars have long studied the correlation between futures market and carbon emission trading rights. Oberndorfer et al. [1] believed that carbon emission trading rights would eventually affect stock returns. Convery and Redmond [2] studied the impact of EU carbon emission pricing and found that energy price is the most important driving factor for carbon trading price. Domestic scholars have also conducted related studies. Chen Xiaohong and Wang Zhiyun [3] verified energy segmentation and found that market supply and demand are important factors affecting the trading price of carbon emission rights. Zou Shaohui et al. [4] studied the dynamic relationship between foreign carbon futures markets and domestic carbon prices, and found that there is a long-term stable relationship between international carbon futures prices and domestic carbon prices, showing an obvious one-way causality. The domestic carbon market lacks pricing power, so it has a weak influence on the international carbon futures market and is in a passive position. Zhang Yuejun et al. [5] introduced mean regression theory, GED-GARCH model and VAR method to investigate the operational characteristics of EU ETS carbon futures market. Wang Dan et al. [6] studied the relationship between spot price and futures price, and found that carbon spot price and futures price have different degrees of influence. There is a long-term equilibrium between the two, but in the short term, they deviate somewhat due to the influence of specific market factors. Futures market involves investors' expectation and judgment of the market. Compared with spot trading, futures market is more speculative, with more flexible prices and frequent fluctuations, which increases market risks. The above studies have all proved that the carbon futures market and the carbon spot market have a longterm stable relationship.

With the establishment of China's carbon emission right trading point, the relationship between carbon emission trading and stock returns of energy companies attracted the interest of scholars. Through research, Tao Chunhua [7] found that there is a significant negative correlation between stock market returns of high carbon emission industries and Shanghai carbon emission market prices. Dutta and Bouri [8] used the binary VAR-GARCH method, and found that there was a significant positive correlation between the price change of Kua and the stock return of renewable energy. Bu Wenke et al. [9] compared and analyzed the relationship between the stock price and carbon emission right price of the new and old energy companies by constructing VAR model and using impulse response and variance analysis. The research found that: there is a long-term equilibrium relationship between the stock price and carbon emission right price of the two types of energy companies, which are significantly

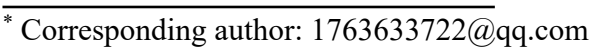


affected by carbon emission right price; the stock prices of traditional energy companies are negatively affected by the carbon emission price in the short term, but positively affected in the long term. Shares of new energy companies are mainly positively affected by the price of carbon emission permits. Paramati et al. [10] verified that renewable energy consumption greatly reduces $\mathrm{CO} 2$ emissions and increases economic output of G20 countries. The empirical results of Zhu Dongshan and Kong Ying [10] show that the carbon trading price in Shenzhen has a positive impact on the stock prices of companies with the concept of low carbon economy. Liu Jixian and Zhang Zongyi [11] found that the impact of carbon futures price on energy stock price is not significant. Zou Shaohui et al. [12] constructed the MSVAR model to describe the nonlinear dynamic relationship among energy futures market, energy stock market and carbon market. The empirical results show that there are structural changes and nonlinear characteristics among energy futures market, energy stock market and carbon market.

\section{2 research method}

\subsection{Vector autoregressive model}

The traditional vector auto regression (VAR) model is as follows:

$$
y_{i}=\varphi_{1} y_{i-1}+\varphi_{2} y_{i-2}+, \cdots,+\varphi_{p} y_{i-p}+\varepsilon_{i}
$$

Among them, $p$ Represents the number of valid lag periods, $\varphi_{j}$ is an n times $\mathrm{n}$ order coefficient matrix, $\varepsilon_{i}$ is a random disturbance term that obeys Gaussian white noise distribution. However, VAR model often ignores the structural changes and nonlinear characteristics of time series. Referring to the relevant literature, it is found that the vector autoregressive model (VAR) of Markov switching proposed by Hamilton can make up for the defects that VAR model cannot find the structural changes and nonlinear characteristics of time series. Therefore, MSVAR model is introduced in this paper.

\subsection{Vector autoregressive model of Markov regime transformation}

MSVAR model represents different states in different periods, and its transition probability can be expressed as:

$$
\left\{\begin{array}{l}
P_{r}\left[s_{i}=1 / s_{i-1}=1\right]=p \\
P_{r}\left[s_{i}=0 / s_{i-1}=1\right]=1-p \\
P_{r}\left[s_{i}=0 / s_{i-1}=0\right]=q \\
P_{r}\left[s_{i}=1 / s_{t-1}=0\right]=1-q
\end{array}\right.
$$

Among them, $P_{r}$ is the probability, if the current state is in the first state $\left(\mathrm{S}_{\mathrm{i}-1}=1\right)$, then the probability that the next phase $\left(\mathrm{S}_{\mathrm{i}}=1\right)$ will still be in the same state is $\mathrm{P}$, if it is in the 0th state $\left(\mathrm{S}_{\mathrm{i}-1}=0\right)$, then the probability that the next phase $\left(S_{i}=0\right)$ will still be in this state is $q$, and the probability formula in formula (2) is:

$$
P=\left(\begin{array}{cc}
p & 1-q \\
1-p & q
\end{array}\right)
$$

Formula (2) can be further expressed by formula (3) as follows:

$$
\left\{\begin{array}{l}
P_{r}\left[s_{i}=1 / s_{i-1}=1\right]=p_{11} \\
P_{r}\left[s_{i}=0 / s_{i-1}=1\right]=p_{21} \\
P_{r}\left[s_{i}=0 / s_{i-1}=0\right]=p_{12} \\
P_{r}\left[s_{i}=1 / s_{t-1}=0\right]=p_{12}
\end{array}\right.
$$

According to the above equation, the relationship between the state variable $\mathrm{S}_{\mathrm{i}}$ and the Markov chain can be obtained:

$$
P_{r}\left[s_{i}=j / s_{i-1}=i\right]=p_{j i}
$$

\section{3 model building}

\section{1 variable selection}

The data used in this paper were selected from the CSMAR and Shenzhen Carbon Emission Exchange, covering the period from August 2013 to March 2021. This paper selects the trading data of the carbon emission trading right in Shenzhen, and this variable is represented by SZA. The CSI energy futures composite index is selected as the proxy variable of the energy futures market, which is represented by CFCI. The arithmetic average price of 50 stocks in the Mainland New Energy Theme Index of China Securities Exchange is selected as the proxy variable of the new energy stock market, which is represented by CNE. At the same time, in order to reduce the heteroscedasticity and error of the time series, the original time series was processed by natural logarithm.

\subsection{MSVAR model}

In this paper, we use SZA, CFCI and CNE to build MSVAR model. These three indexes can form a threedimensional time series vector $y_{t}=\left(y_{1 t}, y_{2 t}, y_{3 t}\right)$, this time series can construct p-order VAR model under state $\mathrm{Si}$ :

$$
\mathrm{y}_{\mathrm{t}}=\varphi_{1}\left(\mathrm{~s}_{\mathrm{i}}\right) \mathrm{y}_{\mathrm{t}-1}+\varphi_{2}\left(\mathrm{~s}_{\mathrm{i}}\right) \mathrm{y}_{\mathrm{t}-2}+, \cdots,+\varphi_{\mathrm{p}}\left(\mathrm{s}_{\mathrm{i}}\right) \mathrm{y}_{\mathrm{p}-1}+\varepsilon_{\mathrm{t}}
$$

Among them, $S_{i}$ is the state variable with a value of 1 or $2, \mathrm{~S}_{\mathrm{i}}=1$ represents the stationary period, and $\mathrm{S}_{\mathrm{i}}=2$ represents the non-stationary period.

\section{4 empirical research}

In this paper, MSVAR model is applied to study the nonlinear relationship among carbon emission trading (SZA), energy futures market (CFCI) and new energy stock market (CNE), we use ADF test to test the stationarity of VAR model and MSVAR model. The test results show that both the energy futures market (CFCI) and the new energy stock market (CNE) have unit roots, so it is necessary to make difference adjustment to the original time series until the series is stable. The firstorder difference sequences of the three variables all pass the stationarity test, there is no unit root, and they obey the first-order single integral process. Next, Johanson cointegration test was used to verify the existence of cointegration relationship in the original sequence. The test 
results show that at the significance level of $5 \%$, there is no co-integration relationship between the three variables. According to the results of unit root test and cointegration test, SZA, CFCI and CNE all obey first-order integration, and there is no co-integration relationship between variables. Therefore, this paper will use firstorder difference sequence to construct VAR and MSVAR models in the subsequent empirical studies. The firstorder difference sequences of carbon emission trading
(SZA), energy futures market (CFCI) and new energy stock market (CNE) are represented by DSZA, DCFCI and DCNE.

\subsection{VAR model}

According to LR, AIC and SC criteria, the optimal lag is 3 , so the VAR (3) model is established.
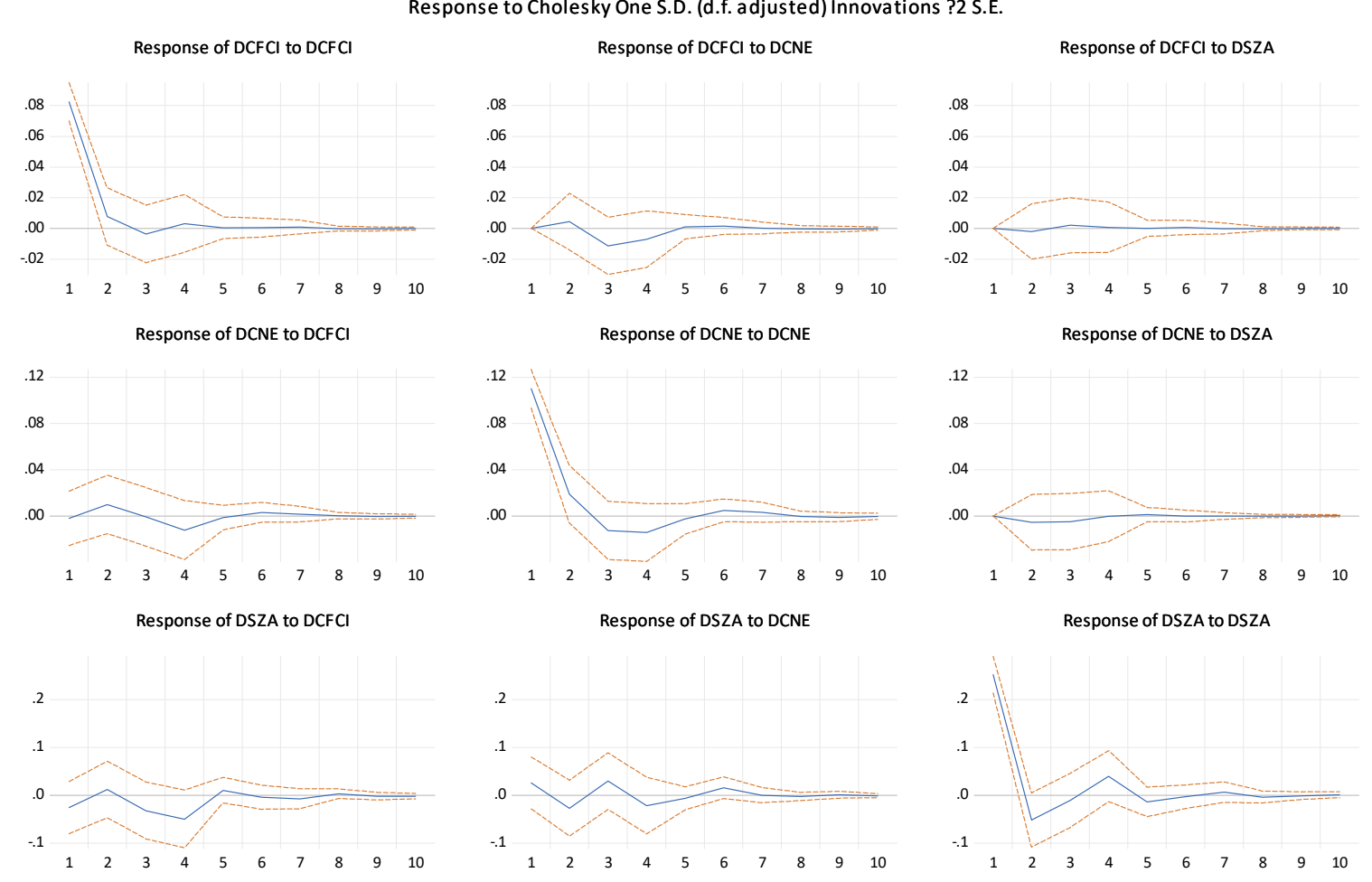

Fig. 1. Impulse response diagram of VAR (3) model

Figure 1 is a VAR (3) the impulse response function of the model, you can see three variables except with their impact is bigger, the smaller the impact of the other two variables, the impact of carbon emissions trading on their own in the first phase from the maximum fell sharply, in 2-4 rising at the rate of small, 4 after a slow and steady; the change of new energy stocks to carbon emission trading in the first four periods is from positive impact to negative impact and then up to positive impact and then down to 0 . After the early stage of the fourth period, the change remains unchanged and remains 0 . The impact of the energy futures market on carbon emission trading also remained unchanged at 0 after the early stage of Phase 4. In the first four stages, the impact increased from negative to positive to the highest point of Phase 2, and then dropped to the lowest point of Phase 3, which was negative, and then rose to 0 again. VAR model shows that there may be more complex relationship between carbon emission trading (SZA), energy futures market (CFCI) and new energy stock market (CNE). Therefore, this paper introduces MSVAR model to further study the nonlinear and structural relationship among the three variables.

\subsection{MSVAR model}

It can be seen from the existing literature and the previous work in this paper that there may be structural changes among the three variables, such as carbon emission trading (SZA), energy futures market (CFCI) and new energy stock market (CNE). Therefore, it is very necessary to conduct a deeper investigation. In this paper, the MS-VAR model was selected for further research, and the optimal lag order was 3 . According to the variation trend of the three variables, the zoning variables were divided into two zoning states: "stationary state" and "non-stationary state". Considering the correlation and other factors, the model finally adopted in this paper is MSIAH (2)-VAR (3). The zoning conversion probability of MSIAH (2)-VAR (3) is shown in Figure 2 and Table 4. The most common zoning conversion occurs from the second half of 2015 to the first half of 2016 and from the second half of 2020 to the first half of 2021 . The results of smoothing the transition probability of the zoning system indicate that there will be a significant structural change in 2015-2016 and 2020-2021, which also indicates that it is necessary to study the structural changes of carbon emission trading (SZA), energy futures market (CFCI) and new energy stock market (CNE). 
As can be seen from the conversion probability of Zoning System, more than half of the sample data fell in Zoning System 1, while the structural changes occurred in 2015, 2016 and 2018. The reason may be that the trading volume of Shenzhen Carbon Emissions Exchange decreased due to the establishment of other carbon emission exchanges in 2015. The most likely reason for the 2018 shift is the impact of the 2008 financial crisis; at the same time, the regional system transition in 2020 May also be influenced by COVID-19. This indicates that the 2-zone VAR model constructed in this paper can better describe the development of the market.

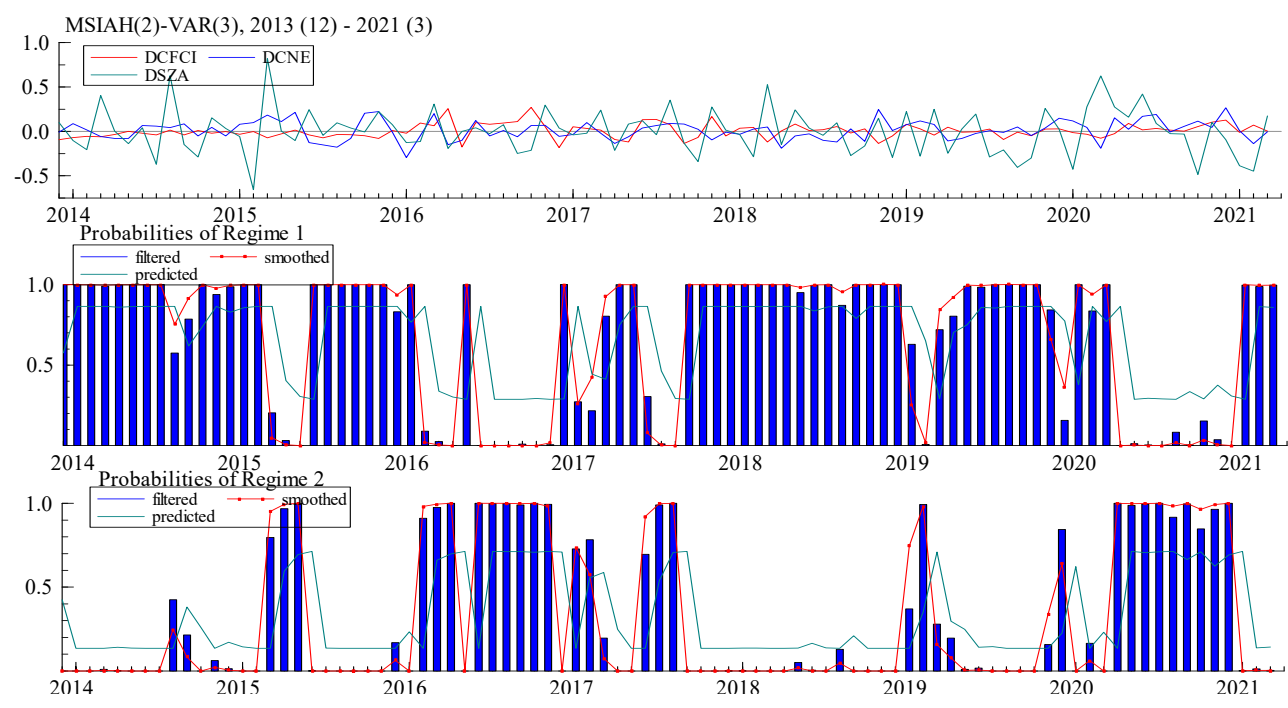

Fig. 2. The zonal conversion probability diagram of MSIAH (2)-VAR (3)

It can be seen from Table 1 that in the sample interval, the "stable" and "non-stable" states of the market have strong continuity, and the continuity of the "non-stable" period is higher than that of the "stable" period. When the current phase is in the "stable" state zone 1, the probability of maintaining the "stable" state 1 in the next phase is 0 . 8644. When the current phase is in the "non-stationary" state zone 2, the probability of maintaining the "nonstationary" state 1 in the next phase is 0.7129 ; meanwhile, the probability of transition from zone 1 stationary market state to non-stationary market state zone 2 is 0.1356 , and the probability of transition from zone 2 non-stationary market state to stationary market state zone 1 is 0.2871 . It shows that the market is stable over a longer period of time.

Table 1. The partition conversion probability matrix of MSIAH(2)-VAR(3)

\begin{tabular}{|c|c|c|}
\hline & Regime 1 & Regime 2 \\
\hline Regime 1 & 0.8644 & 0.1356 \\
\hline Regime 2 & 0.2871 & 0.7129 \\
\hline
\end{tabular}

It can be seen from Table 2 that the degree of correlation between the three markets is different under different sector systems. When the market is in a stable period (Zone 1), the correlation between carbon emission trading and new energy stock market is -0.0373 , and the correlation between carbon emission trading and energy futures market is -0.1430 . When the market is in a non stationary phase (zone 2). The correlation between carbon emission trading and new energy stock market is 0.4919 , and the correlation between carbon emission trading and energy futures market is -0.8141 . The results show that the interaction between energy futures market, new energy stock market and carbon emission trading is generally stronger in the stable period than in the nonstable period, which further proves that there are nonlinear characteristics among energy futures market, new energy stock market and carbon emission trading.

Table 2. Simultaneous correlation of SZA, CFCI and CNE

\begin{tabular}{|c|c|c|c|}
\hline \multicolumn{4}{|c|}{ Regime 1} \\
\hline & DCFCI & DCNE & DSZA \\
\hline DCFCI & 1.0000 & -0.2662 & -0.1430 \\
\hline DCNE & -0.2662 & 1.0000 & -0.0373 \\
\hline DSZA & -0.1430 & -0.0373 & 1. 0000 \\
\hline \multicolumn{4}{|c|}{ Regime 2} \\
\hline & DCFCI & DCNE & DSZA \\
\hline DCFCI & 1. 0000 & -0.3392 & -0.8141 \\
\hline DCNE & -0.3392 & 1.0000 & 0.4919 \\
\hline DSZA & -0.8141 & 0.4919 & 1.0000 \\
\hline
\end{tabular}

\section{Conclusion}

In this paper, the energy market is divided into energy stock market and energy futures market. The carbon market price is represented by the closing price of carbon emission rights in Shenzhen, the energy futures market price is represented by the comprehensive index of energy futures of CSI, and the stock price of listed companies of new energy is represented by the stock market price of new energy. The nonlinear relationship among the three markets is empirically studied by using VAR model and MSVAR model. The empirical results show that the MSVAR model can better explain the nonlinear relationship between the three markets than the traditional VAR model.

Firstly, the unit root and co-integration test results show that there is no co-integration relationship between 
the energy futures market, the new energy stock market and the carbon market. The results of the VAR model show that: in the first phase, the impact of a standard deviation of the CSI energy futures composite index has a negative impact on the carbon market, which turns to a positive impact in the second phase, turns to a negative impact in the third phase and gradually weakens, and disappears in the fourth phase. However, the impact of carbon emission trading price on the energy futures market is weak. A standard deviation shock in the first phase of the new energy stock market will have a positive impact on the carbon emission trading price, which will turn negative in the second phase, positive in the third phase and gradually weaken, and disappear in the fourth phase. However, the carbon market has a weak impact on the new energy stock market. There could be a more complex relationship between carbon market prices, energy company stock prices and energy futures prices.

Secondly, the results of MSVAR model show that it is reasonable to divide the research system into two zones: Zone 1 represents the stationary state of the market, and Zone 2 represents the non-stationary state of the market. Under the two states, the intercept term and coefficient of the model will change with the transition of the zone system, which indicates that the energy futures market and the new energy stock market have different influences on the carbon market under different zone system states. The energy futures market, new energy stock market and carbon market are characterized by nonlinear and structural changes.

At the same time, this paper also has some shortcomings: first, this paper only studied the traditional VAR model and MSVAR model; second, due to the small amount of data, deviations may occur.

\section{References}

1. U. Oberndorfer, Ecol. Econ 68, 4 (2009)

2. F. J. Convery, L. Redmond, Rev. Environ. Econ. Policy 1, 1 (2007)

3. C. Xiaohong, W. Zhiyun, Systems. Eng 30, 2 (2012)

4. Z. Shaohui, Z. Tian, Journal of Shandong University (Natural Science) 53 (2018)

5. Z. Yuejun, W. Yiming, System. Eng. Theor. Prac, 31 (2011)

6. W. Dan, C. Ling, China Population, Resources and Environment, 26, 07 (2016)

7. T. Chunhua, J. Beijing. Jiaotong. Univ(Soc Sci Ed) 14, 04 (2015)

8. A. Dutta, E. Bouri, M. H. Noor, Energy 164 (2018)

9. P. Wenke, Z. Mengen, Price:Theory \& Practice 03 (2020)

10. S. R. Paramati, D. Mo, R. Gupta, Energy. Econ 66, 8 (2017)

11. Z. Dongshan, K. Ying, Ecol. Econ 32, 01 (2016)

12. L. Jixian, Z. Zongyi, Z. Yin, Economist 04 (2013)

13. Z. Shaohui, Z. Tian, Systems. Eng 38, 05 (2020)
14. L. Zhi, L. Boqiang, X. Jiajun, J. Financ. Econ 000, 001 (2014)

15. V. Monbet, P. Ailliot, Comput. Stat. Data. Anal 108 (2017) 